\title{
Lack of SYT-SSX Fusion Transcripts in Malignant Peripheral Nerve Sheath Tumors on RT-PCR Analysis of 34 Archival Cases
}

\author{
Elena Tamborini, Viviana Agus, Federica Perrone, Daniela Papini, Roberta Romanò, \\ Barbara Pasini, Alessandro Gronchi, Maurizio Colecchia, Juan Rosai, \\ Marco A. Pierotti, and Silvana Pilotti
}

Department of Pathology (ET, VA, FP, DP, RR, MC, JR, SP), Preventive Medicine Unit (BP); Department of Musculo-Skeletal Surgery (AG); and Department of Experimental Oncology (MAP), Istituto Nazionale per lo Studio e la Cura dei Tumori, Milano, Italy

SUMMARY: The translocation $\mathrm{t}(\mathrm{X} ; 18)$ is currently regarded as a specific molecular marker of synovial sarcoma (SS). Recently, however, it has been reported that malignant peripheral nerve sheath tumors expressed this marker in $75 \%$ of the cases. To test independently this iconoclastic claim, a molecular analysis for the detection of the SYT-SSX fusion genes was carried out using archival material of 34 consecutive cases diagnosed as malignant peripheral nerve sheath tumors and treated in our Institute from 1998 to 2000. In four of these cases, the molecular analysis on fixed tissues was supplemented with an analysis on fresh frozen tissue. RNA extracted from formalin-fixed paraffin-embedded tissue blocks was evaluated for the presence of SYT-SSX1 and SYT-SSX2 fusion transcripts by RT-PCR. This analysis was extended to a wide variety of normal tissues simultaneously extracted and equally processed. Only two of the cases studied harbored SYT-SSX1 and SYT-SSX2 fusion transcripts, respectively. The diagnostic reevaluation of these two cases in light of the molecular data disclosed that one had the features of a monophasic SS and the other was compatible with that entity. Both of these tumors were strongly immunoreactive for bcl-2, confirming the diagnostic utility of this marker in this instance. Our results reaffirm the specificity of SYT-SSX for SS and suggest that an opposite claim made in a recent study may have been due to a faulty interpretation of the molecular results caused by a contamination of the samples. (Lab Invest 2002, 82:609-618).

$D$ espite its morphologic variability and controversial histogenesis, synovial sarcoma (SS) is a morphologically well defined entity (Enzinger and Weiss, 2001). Additional strong support for the distinctiveness of SS was provided by the demonstration of Turc-Carel and colleagues (Turc-Carel et al, 1987) of the common occurrence in this tumor of the $t(X ; 18)$ chromosomal translocation, a finding later confirmed by many other authors (Dal Cin et al, 1992; Griffin and Emanuel, 1987; Limon et al, 1989; Noguera et al, 1998a; Smith et al, 1987; Sreekantaiah et al, 1994; Ueda et al, 1988). Subsequent molecular studies have shown that this translocation results in the gene fusion SYT-SSX, of which several variants have been described (Agus et al, 2001).

Cytogenetic and molecular studies carried out in many laboratories have confirmed the high frequency

Received January 25, 2002.

Elena Tamborini and Viviana Agus equally contributed to the study. Juan Rosai, Marco A. Pierotti, and Silvana Pilotti were senior co-authors. This work was supported by the Ministero della Sanita, Ricerca Finalizzata 1998-ICS030.1/RF98.32, Italy; AIRC 2001 (Associazione Italiana per la Ricerca sul Cancro), grant 420.198.022.

Address reprint requests to: Dr. Silvana Pilotti, Department of Pathology, Istituto Nazionale per lo Studio e la Cura dei Tumori, via G. Venezian, 1, 20133 Milano, Italy.E-mail:pilotti@istitutotumori.mi.it of this alteration in SS and have provided strong evidence of its specificity for this tumor type (Guillou et al, 2001; van de Rijn et al, 1999). Consequently, cytogenetic demonstration of $\mathrm{t}(\mathrm{X} ; 18)$ or molecular demonstration of the gene fusion resulting from this event have been increasingly regarded as valid criteria for a diagnosis of SS in cases for which the diagnosis was uncertain on morphologic and immunohistochemical grounds or where the presence of unusual changes (Krane et al, 1999; van de Rijn et al, 1999; Winnepennickx et al, 2001) or the occurrence in rare sites (Aubry et al, 2001; Billings et al, 2000; Fritsch et al, 2000; Gunnlaugur et al, 1996; Hisakoa et al, 1999; Kashima et al, 1997; Kim et al, 2000; McKinney et al, 1992; Miettinen et al, 1987; Nicholoson et al, 1997; Shmookler et al, 1982; Witkin et al, 1989; Yu et al, 1996) result in diagnostic dilemmas. Similarly, an unexpected site of the tumor, that is, intraneural growth (O'Connell et al, 1996), can render the diagnosis challenging. In particular, among spindle cell sarcomas, molecular assessment of the specific fusion transcript has been found helpful for the differential diagnosis of monophasic SS from malignant peripheral nerve sheath tumor (MPNST), which can be extremely difficult on occasions (Christensen et al, 1988; Folpe et al, 1998). 
The fact that the molecular evaluation can be carried out in routine formalin-fixed, paraffin-embedded material has greatly increased the practical use of this methodology (Argani et al, 1998; Guillou et al, 2001; Lasota et al, 1998). However, this situation of apparent consensus was recently upset by an article claiming that approximately $75 \%$ of MPNSTs are accompanied by SYT-SSX (O'Sullivan et al, 2000). This startling finding, if confirmed, would obviously nullify the value of molecular testing in this situation while raising the intriguing question of possible pathogenetic relationships between these two neoplasms. Because the results and conclusions of the above-mentioned article are so disparate from those of all other extant studies and its implications so wide-ranging (Dos Santos et al, 2001), we decided to evaluate our own material to test its veracity. At variance with what was observed by O'Sullivan and colleagues and in agreement with unpublished data collected from several laboratories and recently reported as letters to the editor (Ladanyi et al, 2001), we identified only 2 (5.8\%) of 34 cases as having $t(X ; 18)$. Moreover, after morphologic and immunophenotypic reevaluation, these tumors were classified as SS and consistent with SS, respectively.

\section{Results}

\section{Histology and Immunoprofile}

Among the 15 neurofibromatosis type I (NF1)-related patients, there were 13 microscopically conventional MPNSTs (one patient had two independent tumors; three of the tumors had focal epithelioid features), one was a pure epithelioid MPNST (Case 6, Table 1), and one was a so-called malignant Triton tumor (Case 9, Table 1). The immunophenotypical profile of these cases is listed in Table 1. One or more neural-type markers (S-100 protein, CD56, nerve growth factor receptor (NGFR) CD57) were detected immunohistochemically in all but one case. The marker bcl-2 was strongly expressed in one conventional MPNST (Case 10, Table 1) and in the cytoplasm of the epithelioid tumor cells-whether occurring in a pure form (Case 6) or focally-in otherwise conventional MPNSTs. Desmin and myogenin were focally positive in the single malignant Triton tumor (Case 9, Table 1). All 15 tumors were negative for high molecular weight cytokeratins (HMWCKs), AE1/AE3, and CAM 5.2. One case (Case 2) showed a focal profile for epithelial membrane antigen (EMA).

Among the 19 sporadic cases, 16 were microscopically conventional MPNSTs (2 with focal epithelioid features) and 3 were pure epithelioid MPNSTs. Fifteen of the sporadic cases showed gross evidence of origin from a nerve or neural plexus: median plexus two (Cases 3 and 19), brachial plexus three (Cases 11, 13, and 14), sciatic two (Cases 12 and 15), tibial one (Case 2 , of which the lung metastasis has been analyzed), plantar one (Case 16). In three cases there was evidence of involvement of paraspinal nerves (Cases 1,5 , and 7) and in three cases head-neck nerves (facial nerve in Case 6, hypoglossal nerve in Case 8, and vagus nerve in Case 9).

The immunophenotypical profile of these tumors is listed in Table 2. One or more of the above-listed neural markers were expressed in 18 tumors $(94.7 \%)$. There was a strong bcl-2 immunoreactivity in three cases of conventional MPNSTs and in the cytoplasm of the epithelioid tumor cells in the two tumors having this component. All 19 cases were negative for HMWCKs, AE1/AE3, CAM 5.2, and EMA.

\section{Molecular Analysis}

The SYT-SSX fusion transcript was detected in only two of the cases: Case 17(Table 2), which showed the SYT-SSX2 type, and Case 18 (Table 2), which showed the SYT-SSX1 type (Fig. 1A). In the latter case, the fusion transcript was only detected in fresh frozen material. Direct sequencing of the two PCR reactions confirmed the presence of the standard SYT-SSX1 and SYT-SSX2 fusion transcripts (Fig. 1B). Case 10 (Table 1), which showed a strong bcl-2 immunoreactivity, was also analyzed for the presence of SYTSSX4 transcript, with a negative result.

\section{Review of the Two SYT-SSX Positive Cases}

Case 17, Table 2 (SYT-SSX2). A 71-year-old man presented with a tumor in the soft tissue of the left arm that was treated by local excision. The tumor recurred locally three times, the first two recurrences were treated by surgery and the third by radiation therapy. Microscopically, the tumor was hypercellular and monophasic, being predominantly composed of spindle cell admixed with a minor component of oval cells. The contrast between the dark hyperchromatic nuclei and the clear cytoplasm resulted in a "punched-out" appearance of these nuclei. Myxoid change was present focally. Mast cells were numerous. Immunohistochemically, the tumor cells were reactive for vimentin (data not shown), bcl-2, CD56 and NGFR (the latter focally), and negative for S-100 protein, HMWCKs, AE1/AE3, CAM 5.2, EMA, and CD34 (not shown). The revised microscopic diagnosis was spindle cell sarcoma consistent with monophasic SS, and was confirmed molecularly.

Case 18, Table 2 (SYT-SSX1). A 66-year-old woman presented with a tumor of the soft tissues of the left arm. A local excision was followed by amputation, but lung metastases developed shortly thereafter. Microscopically, the tumor was hypercellular and relatively monomorphic. Oval-shaped cells predominated, with a minor component of spindle and round cells. The nuclei had a "punched-out" appearance similar to that seen in the previous case. Areas of prominent nuclear palisading were seen. There were foci of vascular invasion. The recurrent tumor had a similar morphology except that nuclear palisading was no longer identifiable. Immunohistochemical evaluation of the 


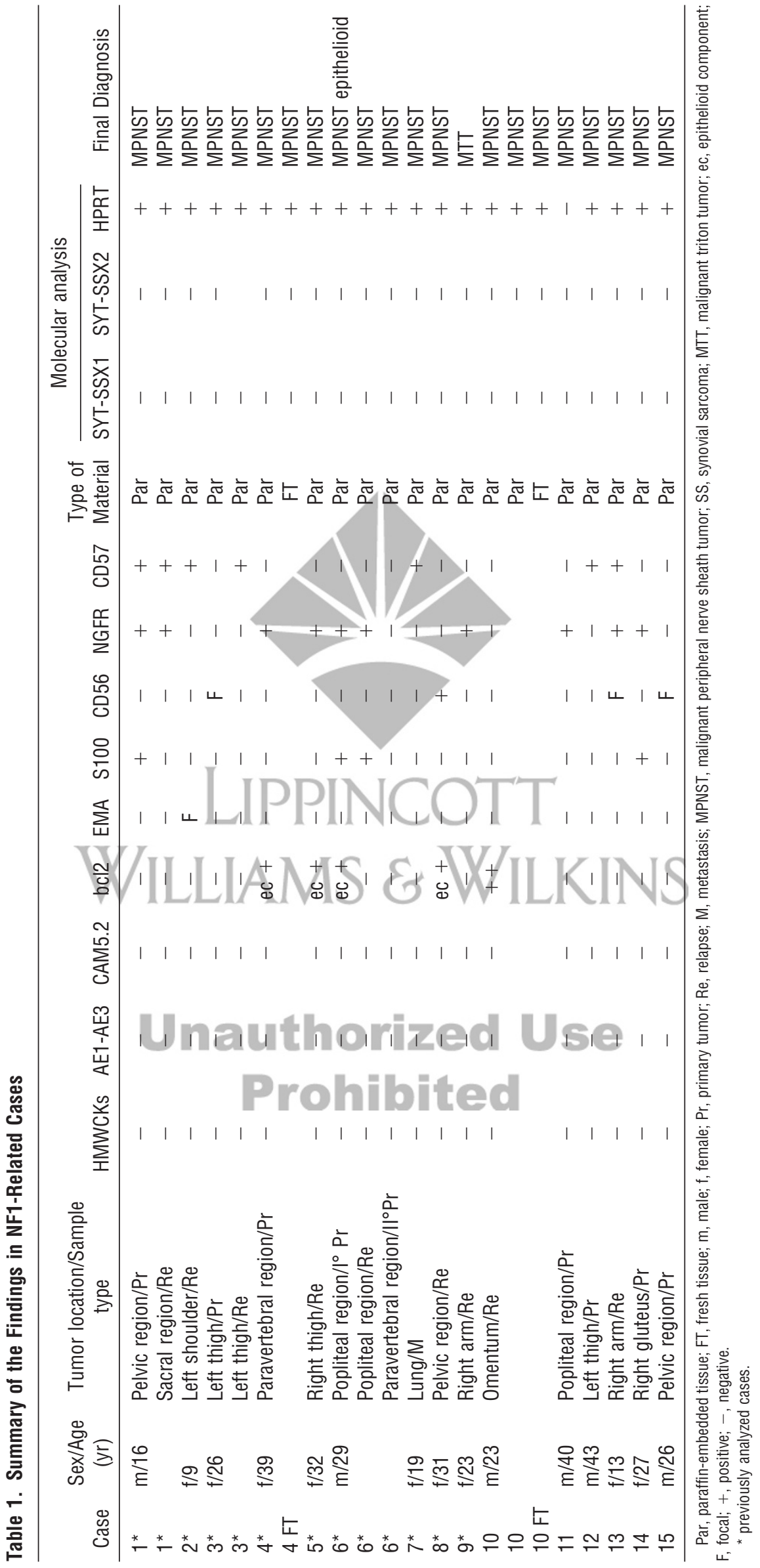




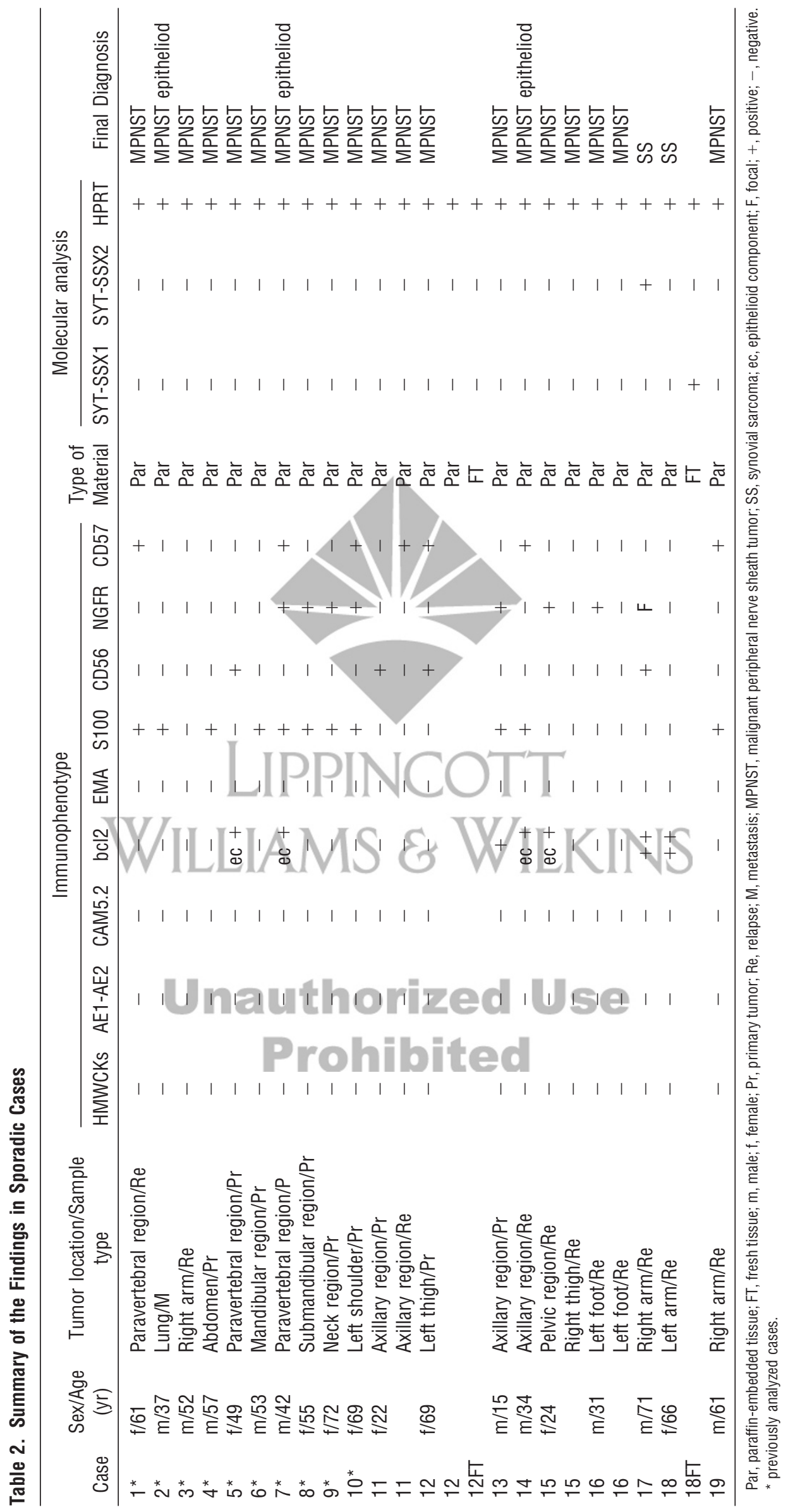


A

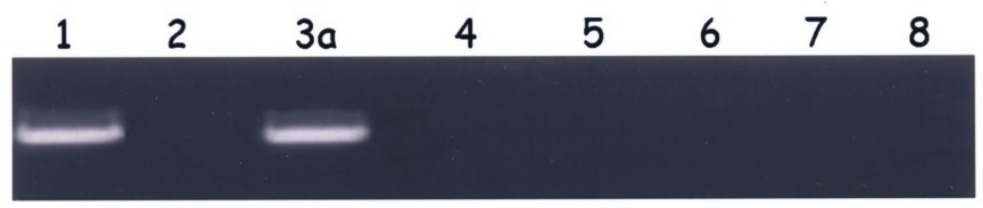

SYT-SSX1

$3 b$

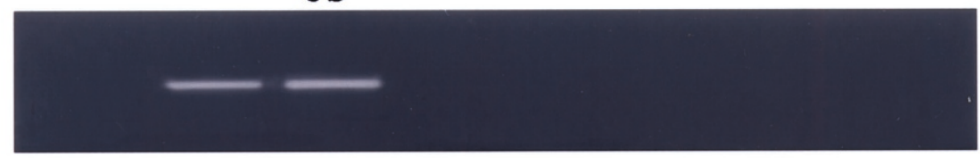

SYT-SSX2

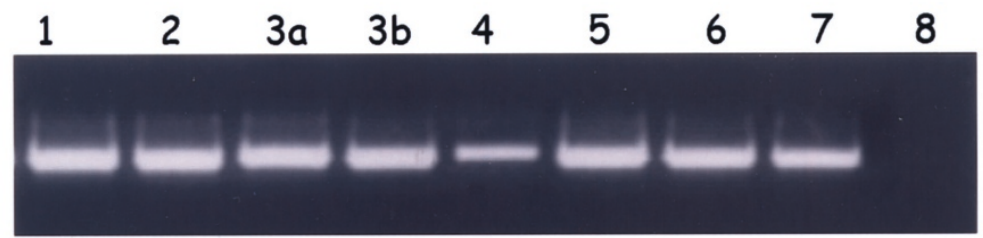

HPRT

breakpoint
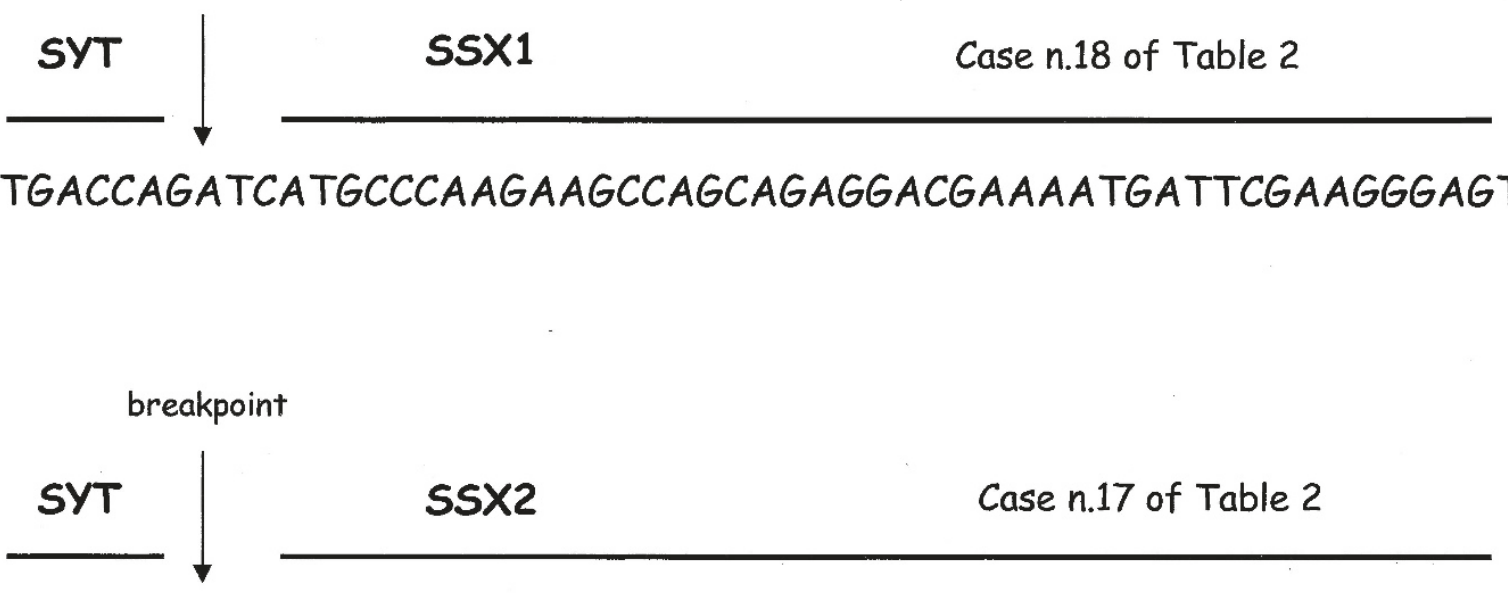

\section{TGACCAGATCATGCCCAAGAAGCCAGCAGAGGAAGGAAATGATTCGGAGGAAGT}

\section{Figure 1.}

A, Gel electrophoresis of the PCR performed on our case material. Here only the two positive cases detected are reported. Lane 1: Case 18, Table 2. Lane 2: Case 17, Table 2. Lane 3: positive controls. Synovial sarcomas already characterized as SYT-SSX1 (3a) and SYT-SSX2 (3b). Lane 4: Normal kidney from frozen tissue. Lane 5: Normal lung from frozen tissue. Lane 6: Normal liver from paraffin-embedded tissue. Lane 7: Normal muscle from paraffin-embedded tissue. Lane 8: no DNA was added to the PCR reaction. B, Electropherograms obtained from PCR sequencing of Cases 17 and 18, Table 2

original tumor showed reactivity for bcl-2, accompanied by negativity for HMWCKs, AE1/AE3, CAM 5.2, EMA, S-100 protein, and NGFR, along with negativity for vimentin, actin, desmin, and CD34 (not shown). On review, it was felt that the morphology and immunohistochemical profile of the tumor were compatible with either a monophasic SS or a MPNST. Whereas the focally prominent palisading pointed torward the latter, the strong immunoreactivity for bcl-2 favored the former, a finding further supported by the molecular detection of the specific gene fusion transcript (SYT-SSX1). 


\section{Discussion}

SS includes two major histologic subtypes, biphasic and monophasic, defined by the presence and absence of glandular epithelial differentiation, respectively, in a background of tumor spindle cells. When presenting with the biphasic appearance, SS is one of the more distinctive morphologic types of soft tissue sarcoma, to the point of being often portrayed as a prototypical example of "instant-pattern recognition" in surgical pathology. Alas, this is not true for the monophasic variant, which is just as common but which shows many overlapping histologic features with other spindle cell sarcomas.

A particularly vexing problem is the distinction between monophasic SS and MPNTS, made more difficult by the less specific and potentially misleading immunohistochemical profile (Christensen et al, 1988; Folpe et al, 1998). Both neoplasms are often microscopically characterized by marked hypercellularity without pleomorphism, a fascicular pattern of growth, and occasional myxoid changes. Immunohistochemically, SSs are often reactive for keratin whereas MPNSTs tend to show positivity (however weak and focal) for S-100 protein. However, up to $30 \%$ of monophasic SS are keratin-negative (Antonescu et al, 2000) and/or S-100 protein-positive, and the reverse is true for MPNST (Guillou et al, 1996). Furthermore, the lack of immunohistochemically detectable neural features in MPNST is not a rare event (Folpe et al, 1998; van de Rijn et al, 1999). Under these circumstances, the detection in SS of a cytogenetic marker and its molecular correlate was hailed as an important theoretical and practical advance in diagnostically doubtful cases (Guillou et al, 2001). Indeed, the only two reported cases (van de Rijn et al, 1999; Zenmyo et al, 2001) of soft tissue sarcoma alleged to be other than SS carrying this alteration were subsequently acknowledged to have been erroneously interpreted by the authors of the respective papers. One of us (JR) had the opportunity to further confirm this association when reviewing a large series of spindle cell sarcomas as a member of the CHAMP group (Chromosome and Morphology in Pathology; data not previously published). Among 27 cases carrying $t(X ; 18), 24$ had been diagnosed as SS and 3 as "consistent with SS" on the basis of their morphologic and immunohistochemical features when reviewed by the pathologists of the group without knowledge of their karyotype. In other words, there was not a single case of spindle cell sarcoma carrying $t(X, 18)$ that had the appearance of an identifiable type of soft tissue sarcoma other than SS.

The belief in the apparent specificity of $t(X, 18)$ and SYT-SSX for SS has been shaken by the recent report by O'Sullivan et al (2000) stating that they found the above molecular alteration in as many as $75 \%$ of their MPNSTs. The theoretical and practical implications of this startling claim are obvious, as elaborated in an editorial (Pfeifer et al, 2000) on the relative role of morphology and genetics in tumor diagnosis and the spirited rebuttals that followed (Fletcher et al, 2001;
Ladanyi et al, 2001). At the practical level, the confirmation of this finding would have essentially invalidated the utility of SYT-SSX for the diagnosis of SS, at least as far as its differential diagnosis with MPNST is concerned. Viewed from another angle, it would have given support to the notion of a possible relationship between SS and MPNST, a possibility raised by some authors (Noguera et al, 1998b; Vang et al, 2000).

Our results were in agreement with those of the literature on the subject (Argani et al, 1998; Fletcher et al, 2001; Guillou et al, 2001; Lasota et al, 1998) and radically at odds with those of O'Sullivan et al (2000). Unpublished data obtained from five different laboratories and quoted in a letter to the editors published in the same journal, pointed out that only 1 of 144 samples of MPNST tested by karyotype (115 cases) or by RT-PCR on RNA extracted from frozen tumor tissues (29 cases) was positive for SYT-SSX (Ladanyi et al, 2001). In the present series, there were only two tumors bearing SYT-SSX. Of these, the first was thought on review to be a monophasic SS and the second to be compatible with this diagnosis. Interestingly, both of these tumors were strongly immunoreactive for bcl-2, whereas this was true for only 1 of the 32 SYT-SSX-negative cases (Case 10), confirming the utility of this marker in the identification of SS (Hirakawa et al, 1996; Mancuso et al, 2000; Pilotti et al, 1998). Another interesting result concerning bcl-2 was the cytoplasmic positivity consistently seen in the epithelioid tumor cells of MPNST, whether occurring in a pure form or as a focal feature in otherwise conventional tumors. There may be a functional significance to this relationship, as supported by the fact that the only epithelioid MPNST lacking this reactivity (Case 2, Table 2) was found in a previous study (Birindelli et al, 2001) to carry a missense TP53 mutation, thus indicating an impairment in the apoptosis pathway. Taken as a whole, our results underscore the close similarity between SS and MPNST and reaffirm the utility of molecular testing in this situation.

The fact, as graphically stated elsewhere (Fletcher et al, 2001), that the findings by O'Sullivan et al "fly directly in the face of the results obtained in other comparable studies or by other techniques " (including ours) led inescapably to the suspicion that either their interpretation of the morphology or the molecular tests is mistaken. The former is highly unlikely. Although the misinterpretation of MPNST as SS is certainly possible (as our own article again demonstrates), it stretches the imagination to assume that this mistake would have been made for all of the cases included in the article in question, considering the fact that many of the tumors occurred in patients with NF1 and/or within major nerve trunks and that the morphologic evaluation of the cases was done by highly skilled and experienced pathologists, who are all too aware of the pitfalls in the area. By exclusion, misinterpretation of the molecular results seems much more likely, especially when one considers that the search for fusion transcripts was carried out using paraffin-embedded material and knowing the contamination problems that can occur in such tissues, 
related to the relatively less stringent PCR conditions that are necessary to amplify cDNA. To avoid this problem and to verify the specificity of SYT-SSX fusion transcript detection, we used several types of normal tissue to perform two types of internal controls, one at the level of RNA extraction using paraffinembedded material and the other during the amplification procedure using snap-frozen material. The former was aimed at the assessment of the quality of the RNA extraction and the latter at a verification of the specificity of the PCR amplification. By using these normal cDNAs as negative controls in each amplification procedure, we disregarded all of the experiments in which normal tissue cDNAs showed positivity for $t(X ; 18)$. This was true for 18 tumors analyzed in 2 distinct sets of experiments, corresponding to $46 \%$ of cases, all of which were subjected to a new RNA extraction procedure.

A possible additional bias introduced by O'Sullivan et al (2000) was their choice for sequencing the cloned PCR product to confirm the presence of the translocation. By doing so, small amounts of PCR contaminants can also be cloned in the vector, thus leading to an overestimation of the number of SYT-SSX positive samples.

In summary, our results reaffirm the recently challenged notion that the finding of SYT-SSX fusion is a highly specific and sensitive marker of SS, in agreement with published (Christensen et al, 1988; Folpe et al, 1998) and unpublished results obtained in several laboratories (Ladanyi et al, 2001). In addition, our results show that the sensitivity remains high in formalin-fixed paraffin-embedded material, while acknowledging the fact that examination of fresh frozen tissue provides superior results (as our Câse, 18 demonstrates).

\section{Materials and Methods}

\section{Samples and Patients}

Forty-three formalin-fixed, paraffin-embedded samples from 34 cases that had been diagnosed as MPNST and treated at the National Cancer Institute (Milan) from 1989 to 2000 were analyzed. The cases were consecutive except for the exclusion of Bouinfixed samples (Guillou et al, 2001). The first nine cases listed in Table 1 and the first 10 cases listed in Table 2 had been included in a previous article from our group describing alterations of the Rb and TP53 pathways in MPNSTs (Birindelli et al, 2001).

The medical records were evaluated by a medical geneticist (BP), who classified the cases according to officially coded National Institutes of Health Neurofibromatosis Consensus Development Conference criteria (National Institute of Health, 1998). Fifteen patients were classified as NF1 with an associated MPNST (Table 1); 19 subjects were classified as sporadic tumor patients because no clinical signs or family history of NF1 were present (Table 2). One of the patients in the first group (Case 6, Table 1) had two independent primary tumors. In three NF1-associated cases (Table 1, Cases 1, 3, and 6) and in one sporadic case (Table 2, Case 11), the analysis was carried out on the primary tumors as well as on the recurrence(s). In five cases, two of which were NF1-associated (Table 1, Cases 4 and 10) and two sporadic (Table 2, Cases 12 and 18), frozen tumor material was also available and this was molecularly characterized in parallel with the paraffin-embedded material.

\section{Diagnostic Criteria for MPNST}

The criteria applied for the diagnosis of usual MPNST were morphologic, immunophenotypic, and/or topographic. Morphologically, the tumors were made up of spindle cells with indistinct cytoplasm margins and wavy or S-shaped nuclei, arranged in fascicles with alternating cellular and myxoid areas. Tumors with these features were required to show either an immunostaining profile suggestive of MPNST, such as a reactivity for at least one of the neural markers (S-100, CD56, NGFR, CD 57) in absence of staining for cytokeratins, and/or clear evidence of origin from a nerve in sporadic cases, or occurrence in patients with NF1. For MPNST (including the epithelioid variant) and Triton tumor, we followed the criteria recommended by Scheithauer et al (1999).

\section{Immunohistochemical Analysis}

Immunoperoxidase phenotyping was performed on paraffin-embedded tissue sections in all cases, using antibodies against the following markers: pool of HMWCKs (clone $34 \beta E 12$, Dako, Glostrup, Denmark; 1:200 mixed with clone KS 8.12, Sigma, St. Louis, Missouri, 1:200); AE1/AE3 (clone AE1+AE3, Dako, 1:50); CAM 5.2 (clone CAM5.2, Becton Dickinson, Heidelberg, Germany, 1:10); EMA (clone E29, Dako, 1:500); bcl-2 (clone 124, Dako, 1:500); S-100 protein (Dako, 1:4,000 diluted);CD56 (clone OB 11, Sigma, 1:500); NGFR (clone ME 20.4, Amersham, Italy, 1:20); and CD57 (clone VC1C, Sigma, 1:50). In one tumor (Case 9, Table 1) immunostaining against desmin (clone D33, Dako, 1:200) and myogenin (F5D, Dako, 1:50) had also been performed. All stains were carried out by the peroxidase-streptavidin method, as previously described (Lavarino et al, 1998). Antigen retrieval for S-100 protein, bcl 2, CD56, desmin, and myogenin was carried out by pretreating the sections at $95^{\circ} \mathrm{C}$ for 6 minutes in autoclave, whereas for NGFR, the pool of HMWCKs, CAM 5.2, and EMA it was achieved with trypsin digestion.

\section{RNA Extraction}

In each case, the sample chosen for molecular analysis was the one deemed most representative on the basis of the hematoxylin-eosin-stained sections. In two cases (Case 10, Table 1, Case 12, Table 2), two blocks from the same surgical specimen were analyzed. To verify the specificity of the subsequent experiments, at least two samples of paraffinembedded and snap-frozen normal tissue were also processed for each set of RNA extraction. 
RNA from paraffin-embedded MPNSTs and normal tissues was extracted from three to five $5-\mu \mathrm{m}$ sections. Tissue samples were deparaffinized in two changes of xylene and three washes with 100\% ethanol. After drying, tissue pellets were resuspended in $800 \mu$ l of lysis buffer (20 mm TrisHCl pH 8.0, 20 mm EDTA, $2 \%$ SDS, $4 \mathrm{mg} / \mathrm{ml}$ proteinase $\mathrm{K}$ ) and incubated overnight at $55^{\circ} \mathrm{C}$ in a continuous gentle shaker. After incubation, $1 \mathrm{ml}$ of RNAzol B (Gibco BRL, Grand Island, New York) was added to each sample. Five tumor specimens, for which snap-frozen sample was also available, were directly extracted by homogenizing the tissue in $1 \mathrm{ml}$ of RNAzol B according to the manufacturer's instructions. The RNA pellets were reconstituted in sterile water and stored at $-80^{\circ} \mathrm{C}$.

\section{Reverse Transcriptase PCR (RT-PCR)}

One microgram of total RNA was reverse-transcribed with Superscript reverse transcriptase (GIBCO) using both oligo dT and random examers, following the manufacturer's instructions. Thirty microliters of sterile TE $\mathrm{pH} 8.0$ was added to $20 \mu \mathrm{l}$ of total volume of CDNA obtained from each sample. All samples were tested for cDNA integrity by the amplification of HPRT housekeeping gene (not shown) and subsequently analyzed for the presence of the SYT-SSX1 and SYT-SSX2 fusion transcripts. As negative and quality controls, cDNAs from both frozen and paraffin-embedded normal tissues were also amplified. For paraffinembedded samples, $6 \mu$ of $50 \mu$ reaction were used to selectively amplify the SYT-SSX fusion transcripts and the housekeeping gene HPRT. In snap-frozen samples, $1 \mu$ l of cDNA was amplified.

The following primers were used for the amplifications: SYT int: 5'-AGACCAACACAGCCTGGACCA-3'; SSX1: 5'-GGTGCAGTTGTTTCCCATCG-3'; SSX2: 5'GGCACAGCTCTTTCCCATCA-3'; HPRT F: 5'-GCTTGCTGGTGAAAAGGAC-3'; HPRT R: 5'-GTCAAGGGCATATCCTACAAC-3'.

All PCR reactions (SYT int/SSX1, SYT int/SSX2, and HPRT F/HPRT R) were performed using Gold Taq (Applera Europe). The PCR conditions were the following: 8 minutes of denaturation at $96^{\circ} \mathrm{C}$, and then by 35 cycles of 30 seconds at $94^{\circ} \mathrm{C}, 30$ seconds at $57^{\circ} \mathrm{C}$, 30 seconds at $72^{\circ} \mathrm{C}$, and a final 5-minute extension step at $72^{\circ} \mathrm{C}$.

The amplification reaction products were separated through $1.8 \%$ agarose gel electrophoresis and visualized with ethidium bromide. For each amplification procedure, one case each of cytogenetically confirmed SYTSSX1 and SYTSSX2 SS was used as positive control, and paraffin-embedded and snapfrozen normal human tissues cDNA were used as negative controls. The PCR results were confirmed by two to four repeat amplification procedures.

\section{SYT-SSX4 Fusion Transcript Detection}

On RNA extracted from frozen material, the specific SYT-SSX4 transcript was investigated both by the procedures described by Skytting et al (1999) and by the amplification of DNA with the following oligonucleotides: SYT 500: 5' -GCCATCATCACAGAGCATGC3'; SSX R: 5'-TGCTATGCACCTGATGACGA-3'.

The PCR reaction was performed using Gold Taq (Applera Europe) under the following conditions: 8 minutes of denaturation at $96^{\circ} \mathrm{C}$, and then 35 cycles of $30 \mathrm{sec}$ at $94^{\circ} \mathrm{C}, 1$ minute at $54^{\circ} \mathrm{C}, 1$ minute at $72^{\circ} \mathrm{C}$, and a final 5-minute extension step at $72^{\circ} \mathrm{C}$. The amplification reaction products were analyzed as previously described.

\section{DNA Sequencing}

For samples in which a specific SYT-SSX PCR product was detected, the amplification reaction was directly sequenced with the same primers used for the $P C R$ reaction, using the automatic DNA sequencer Abi PRISM 377A (Applera Biosystem Europe, Roche Molecular Systems, Branchburg, New Jersey). The SYTSSX breakpoint was confirmed by aligning the obtained sequence with the GeneBank database related sequences SYT Acc. X79201, SSX1 Acc. X86174, and SSX2 Acc. X86175, using Sequence Navigator Software (Applera Europe).

\section{References}

Agus V, Tamborini E, Mezzelani A, Pierotti MA, and Pilotti S (2001). A novel type of SYT-SSX4 fusion transcript in Synovial Sarcoma. J Natl Cancer Inst 93:1347-1349.

Antonescu CR, Kawai A, Leung DH, Lonardo F, Woodruff JM, Healey $\mathrm{JH}$, and Ladanyi M (2000). Strong association of SYT-SSX fusion type and morphologic epithelial differentiation in synovial sarcoma. Diagn Mol Pathol 9:1-8.

Argani P, Zakowski MF, Klimstra DS, Rosai J, and Ladanyi M (1998). Detection of the SYT-SSX chimeric RNA of synovial sarcoma in paraffin-embedded tissue and its application in problematic cases. Mod Pathol 11:65-72.

Aubry MC, Bridge JA, Wickert R, and Tazelaar HD (2001). Primary monophasic synovial sarcoma of the pleura: Five cases confirmed by the presence of SYT-SSX fusion transcript. Am J Surg Pathol 25:776-781.

Billings SD, Meisner LF, Cummings OW, and Tejada E (2000). Synovial sarcoma of the upper digestive tract: A report of two cases with demonstration of the $\mathrm{X} ; 18$ translocation by fluorescence in situ hybridization. Mod Pathol 13:68-76.

Birindelli S, Perrone F, Oggionni M, Lavarino C, Pasini B, Vergani B, Ranzani GN, Pierotti MA, and Pilotti S (2001). Rb and TP53 pathway alterations in sporadic and NF1-related malignant peripheral nerve sheath tumors. Lab Invest 81 : 833-844.

Christensen WN, Strong EW, Bains MS, and Woodruff JM (1988). Neuroendocrine differentiation in the glandular peripheral nerve sheath tumor. Pathologic distinction from the biphasic synovial sarcoma with glands. Am J Surg Pathol 12:417-426.

Dal Cin P, Rao U, Jani-Sait S, Karakousis C, and Sandberg AA (1992). Chromosome in the diagnosis of soft tissue tumors. I. Synovial sarcoma. Mod Pathol 5:357-362.

Dos Santos NR, de Bruijn DHR, and van Kessel AG (2001). Molecular mechanisms underlying synovial sarcoma development. Genes Chromosom Cancer 30:1-14. 
Enzinger FM and Weiss SW (2001), editors. Soft tissue tumors, 4th ed. St. Louis: Mosby, 1483-1509.

Fletcher CDM, Fletcher JA, Dal Cin P, Ladanyi M, and Woodruff JM (2001). Diagnostic gold standard for soft tissue tumors: Morphology or molecular genetics? Histopathology 39:100-101.

Folpe AL, Schmidt RA, Chapman D, and Gown AM (1998). Poorly differentiated synovial sarcoma: Immunohistochemical distinction from primitive neuroectodermal tumors and high-grade malignant peripheral nerve sheath tumors. Am J Surg Pathol 22:673-682.

Fritsch M, Epstein JI, Perlman EJ, Watts JC, and Argani P (2000). Molecularly confirmed primary prostatic synovial sarcoma. Hum Pathol 31:246-249.

Griffin CA and Emanuel BS (1987). Translocation (X;18) in a synovial sarcoma. Cancer Genet Cytogenet 26:181-183.

Guillou L, Coindre JM, Gallagher G, Terrier P, Gebhard S, de Saint Aubain Somerhausen N, Michels JJ, Jundt G, Ranchere Vince D, Collin F, Trassard M, Le Doussal V, and Benhattar J (2001). Detection of the synovial sarcoma translocation $t(X$; 18) (SYT; SSX) in paraffin embedded tissue using reverse transcriptase-polymerase chain reaction: A reliable and powerful diagnostic tool for pathologist. Hum Pathol 32:105-112.

Guillou L, Wadden C, Kraus MD, Dei Tos AP, and Fletcher CDM (1996). S-100 protein reactivity in synovial sarcoma. A potentially frequent diagnostic pitfall: Immunohistochemical analysis of 100 cases. Appl Immunohistochem 4:167-175.

Gunnlaugur PN, Shaw PA, Rosenberg AE, Dickersin GR, Young RH, and Scully RE (1996). Synovial sarcoma of the vulva: A report of two cases. Mod Pathol 9:970-974.

Hirakawa N, Naka T, Yamamoto I, Fukuda T, and Tsuneyoshi M (1996). Overexpression of bcl-2 protein in synovial sarcoma: A comparative study of other soft tissue spindle cell sarcomas and an additional analysis by fluorescence in situ hybridization. Hum Pathol 27:1060-1065.

Hisakoa M, Hashimoto H, Iwamasa T, Ishikawa K, and Aoki T (1999). Primary synovial sarcoma of the lung: Report of two cases confirmed by molecular detection of SYT-SSx fusion gene transcripts. Histopathology 34:205-210.

Kashima T, Matshushita H, Kuroda M, Takeuchi H, Udagawa H, Ishida T, Hara M, and Machinami R (1997). Biphasic synovial sarcoma of the peritoneal cavity with $t(X ; 18)$ demonstrated by reverse transcriptase polymerase chain reaction. Pathol Int 47:637-641.

Kim DH, Shon JH, Lee MC, Lee G, Yoon GS, Hashimoto H, Sonobe H, and Ro JY (2000). Primary synovial sarcoma of the kidney. Am J Surg Pathol 24:1097-1104.

Krane JF, Bertoni F, and Fletcher CMD (1999). Myxoid synovial sarcoma: An underappreciated morphologic subset. Mod Pathol 12:456-462.

Ladanyi M, Woodruff JM, Scheithauer BW, Bridge JA, Barr FG, Goldblum JR, Fisher C, Perez-Atayde A, Dal Cin P, Fletcher CDM, and Fletcher JA (2001). Letters to the editor. Mod Pathol 14:733-735.

Lasota J, Jasinski M, Debiec-Rychter M, Szadowska A, Limon J, and Miettinen M (1998). Detection of the SYT-SSX fusion transcripts in formaldehyde-fixed, paraffin-embedded tissue: A reverse transcription polymerase chain reaction amplification assay useful in the diagnosis of synovial sarcoma. Mod Pathol 11:626-633.
Lavarino C, Corletto V, Mezzelani A, Della Torre G, Bartoli C, Riva C, Pieortti MA, Rilke F, and Pilotti S (1998). Detection of TP53 mutation, loss of heterozigosity and DNA content in fine needle aspirates of breast carcinoma. $\mathrm{Br} \mathrm{J}$ Cancer 77:125130.

Limon J, Mrozek K, Nedoszytko B, Babinska M, Jaskiewicz J, Kopacz Azoltowsaka A, and Borowska-Lehman J (1989). Cytogenetic findings in two synovial sarcomas. Cancer Genet Cytogenet 38:215-222.

Mancuso T, Mezzelani A, Riva C, Fabbri A, Dal Bo L, Sampietro G, Perego P, Casali P, Zunino F. Sozzi G, Pierotti MA, and Pilotti S (2000). Analysis of SYT-SSX fusion transcript and bcl2 expression and phosphorylation status in synovial sarcoma. Lab Invest 80:805-813.

McKinney C, Mills S, and Fechner R (1992). Intraarticular synovial sarcoma. Am J Surg Pathol 16:1017-1020.

Miettinen M, Santavirta S, and Slatis P (1987). Intravascular synovial sarcoma. Hum Pathol 18:1075-1077.

National Institutes of Health (1988). Neurofibromatosis. Conference statement. National Institutes of Health Consensus Development Conference. Arch Neurol 45:575-578.

Nicholoson AG, Rigby M, Lincoln C, Meller S, and Fisher C (1997). Synovial sarcoma of the heart. Histopathology 39: 349-352.

Noguera R, Lopez- Gines C, Gil R, Carda C, Pellin A, and Llombart-Bosch A (1998a). Translocation (X;18) in a synovial sarcoma. Cancer Genet Cytogenet 33:311-312.

Noguera R, Navarro S, Cremades A, Rosellò-Sastre E, Pellin A, Peydro-Olaya A, and Llombart-Bosch A (1998b). Translocation $(X ; 18)$ in a biphasic synovial sarcoma with morphologic features of neural differentiation. Diagn Mol Pathol 7:16-23.

O'Connell JX, Browne WL, Gropp PT, and Berean KW (1996). Intraneural biphasic synovial sarcoma: An alternative "glandular" tumor of the peripheral nerve. Mod Pathol 9:738-741.

O'Sullivan MJ, Kyriakos M, Zhu Z, Wick MR, Swanson PE, Dehner LP, Humphrey PA, and Pfeifer JD (2000). Malignant peripheral nerve sheath tumors with $t(X ; 18)$. A pathologic and molecular genetic study. Mod Pathol 13:1336-1346.

O'Sullivan MJ, Wick MR, Kyriakos M, Zhu Z, Swanson PE, Dehner LP, Humphrey PA, and Pfeifer JD (2001). Letters to the editor, reply. Mod Pathol 14:736-737.

Pfeifer JD, Hill DA, O'Sullivan MJ, and Dehner LP (2000). Diagnostic gold standard for soft tissue tumors: Morphology or molecular genetics? Histopathol 37:485-500.

Pilotti S, Mezzelani A, Azzarelli A, Rilke F, and Pierotti MA (1998). bcl2 expression in synovial sarcoma. J Pathol 184: 337-339.

Scheitauer BW, Woodruff JM, and Erlandson RA (1999). Tumors of the peripheral nervous system. In: Atlas of tumor pathology, 3rd series, Washington: AFIP.

Shmookler BM, Enzinger FM, and Brannon RB (1982). Orofacial synovial sarcoma. Cancer 50:269-272.

Skytting B, Nilsson B, Brodin B, Xie Y, Lundeberg J, Uhlen M, and Larsson O (1999). A novel fusion gene, SYT-SSX4, in synovial sarcoma. J Natl Cancer Inst 91:974-975.

Smith S, Reeves BR, Wong L, and Fisher C (1987). A consistent chromosome translocation in synovial sarcoma. Cancer Genet Cytogenet 26:179-180. 
Sreekantaiah C, Ladanyi M, Rodriguez E, and Chaganti RSK (1994). Chromosomal aberrations in soft tissue tumors: Relevance to diagnosis, classification, and molecular mechanisms. Am J Pathol 144:1121-1134.

Turc-Carel C, Dal Cin P, Limon J, Rao U, Li FP, Corson JM Zimmerman R, Perry DM, Cowan P, and Sandberg AA (1987). Involvement of chromosome $\mathrm{X}$ in primary cytogenetic change in human neoplasia: Nonrandom translocation in synovial sarcoma. Proc Natl Acad Sci USA 84:1981-1985.

Ueda T, Aozasa K, Tsujimoto M, Uchida A, Taniwaki M, and Abe $T$ (1988). Translocation $X ; 18$ and insertion 15;11 in a case of synovial sarcoma. Cancer Genet Cytogenet 30:183185.

van de Rijn M, Barr FG, Xiong QB, Hedges M, Shipley J, and Fisher C (1999). Poorly differentiated synovial sarcoma. An analysis of clinical, pathologic, and molecular genetic feature. Am J Surg Pathol 23:106-112.

Vang R, Biddle DA, Harrison WR, Heck K, and Cooley LD (2000). Malignant peripheral nerve sheath tumor with a $t(X$; 18). Arch Pathol Lab Med 124:864-867.
Winnepennickx V, De Vos R, Debiec-Rychter M, Samson I, Brys P, Hagemeijer A, and Sciot R (2001). Calcifying/ ossifying synovial sarcoma shows $t(X ; 18)$ with SSX2 involvement and mitochondrial calcifications. Histopatology 38:141145.

Witkin GB, Miettinen M, and Rosai J (1989). A biphasic tumor of the mediastinum with features of synovial sarcoma: $A$ report of four cases. Am J Surg Pathol 13:490-499.

Yu FH, Kobos JW, and Brooks JSJ (1996). Synovial sarcoma of the parotid gland region: A case report and review of the literature. Int J Surg Pathol 4:239-244.

Zenmyo M, Komiya S, Hamada T, Hirakoa K, Nagata K, Tsuji $\mathrm{S}$, Hashimoto H, and Inoue A (2001). Intraneural monophasic synovial sarcoma: A case report. Spine 26:310-313.

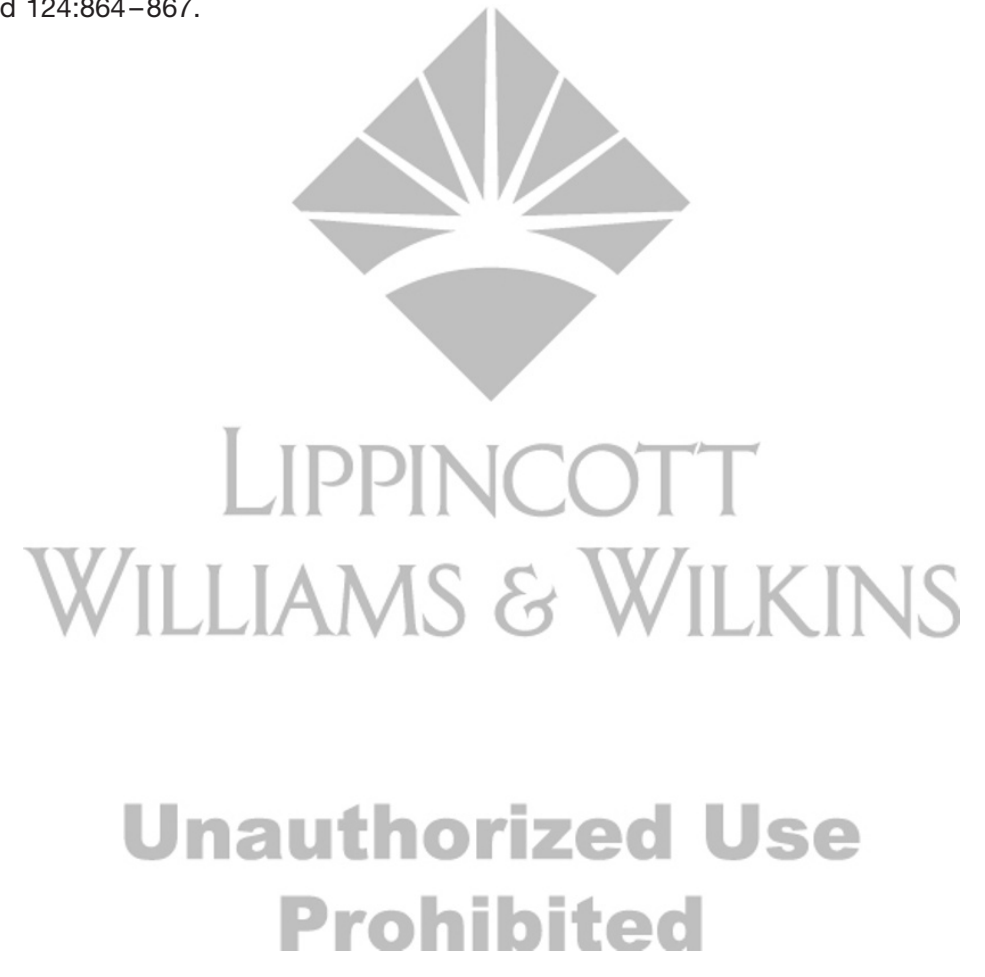

